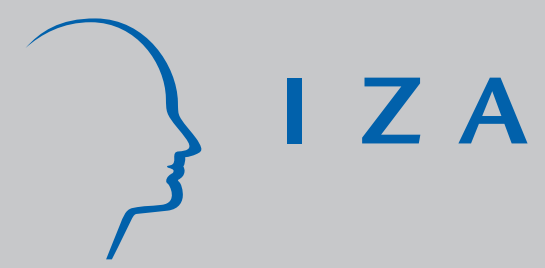

IZA DP No. 9190

Modelling the Joint Distribution of Income and Wealth

Markus Jäntti

Eva Sierminska

Philippe Van Kerm

July 2015

Forschungsinstitut zur Zukunft der Arbeit Institute for the Study of Labor 


\title{
Modelling the Joint Distribution of Income and Wealth
}

\author{
Markus Jäntti \\ SOFI, Stockholm University \\ Eva Sierminska \\ LISER, DIW Berlin and IZA \\ Philippe Van Kerm \\ LISER
}

\author{
Discussion Paper No. 9190 \\ July 2015
}

IZA

P.O. Box 7240

53072 Bonn

Germany

\author{
Phone: +49-228-3894-0 \\ Fax: +49-228-3894-180 \\ E-mail: iza@iza.org
}

\begin{abstract}
Any opinions expressed here are those of the author(s) and not those of IZA. Research published in this series may include views on policy, but the institute itself takes no institutional policy positions. The IZA research network is committed to the IZA Guiding Principles of Research Integrity.

The Institute for the Study of Labor (IZA) in Bonn is a local and virtual international research center and a place of communication between science, politics and business. IZA is an independent nonprofit organization supported by Deutsche Post Foundation. The center is associated with the University of Bonn and offers a stimulating research environment through its international network, workshops and conferences, data service, project support, research visits and doctoral program. IZA engages in (i) original and internationally competitive research in all fields of labor economics, (ii) development of policy concepts, and (iii) dissemination of research results and concepts to the interested public.
\end{abstract}

IZA Discussion Papers often represent preliminary work and are circulated to encourage discussion. Citation of such a paper should account for its provisional character. A revised version may be available directly from the author. 


\section{ABSTRACT}

\section{Modelling the Joint Distribution of Income and Wealth ${ }^{*}$}

This paper considers a parametric model for the joint distribution of income and wealth. The model is used to analyze income and wealth inequality in five OECD countries using comparable household-level survey data. We focus on the dependence parameter between the two variables and study whether accounting for wealth and income jointly reveals a different pattern of social inequality than the traditional 'income only' approach. We find that cross-country variations in the dependence parameter effectively accounts only for a small fraction of cross-country differences in a bivariate measure of inequality. The index appears primarily driven by differences in inequality in the wealth distribution.

JEL Classification: $\quad$ C1, D31, J10

Keywords: income, wealth, inequality, copula, multivariate Gini

Corresponding author:

Eva Sierminska

LISER (Luxembourg Institute of Socio-Economic Research)

3, avenue de la Fonte

L-4364 Esch-sur-Alzette

Luxembourg

E-mail: eva.sierminska@liser.lu

\footnotetext{
* This research is part of the WealthPort project (Household wealth portfolios in Luxembourg in a comparative perspective) financed by the Luxembourg 'Fonds National de la Recherche' (contract C09/LM/04) and by core funding for CEPS/INSTEAD from the Ministry of Higher Education and Research of Luxembourg. Comments from participants to the IARIW $32^{\text {nd }}$ General Conference (Boston) and to the $46^{\text {th }}$ Italian Statistical Society meeting (Rome) are gratefully acknowledged.
} 


\section{Introduction}

Inequality in living conditions within industrialized countries is almost always gauged on the basis of annual household income data, the distribution of which is typically summarized in coefficients such as the Gini index (Jenkins and Van Kerm, 2009). Far less is known about the distribution of other measures of economic well-being, such as consumption expenditure or wealth and asset holdings. The latter is of particular complementary interest as it captures long-term economic resources better than income flows do and represents resources that people are able to draw upon to face adverse shocks.

While there are obvious links between income and net wealth accumulation via savings and borrowing constraints, the relationship between these two variables is bound to be complex and relatively little is known about it empirically, especially outside the United States (Kennickell, 2009). Income, its volatility, savings and dissavings from past income streams and the resulting wealth portfolio allocation choices will shape the association at the household level. The institutional environment (with regards to pensions in particular) may also exert a key influence. We can thus expect differences in the relationship between income and wealth across countries, as indicated by comparative work that has been conducted using data from the Luxembourg Wealth Study (LWS) database (Sierminska et al., 2006, Jäntti et al., 2008, Sierminska et al., 2013, Jäntti et al., 2013). ${ }^{1}$ While wealth and income can, in particular, instances be thought of as an alternative means of securing a standard of living, it is more likely that they are positively associated, thereby reinforcing social inequality overall. Better knowledge about the joint distribution of income and wealth is relevant for the design of taxation and redistribution policies as well as for better identification and targeting of vulnerable population groups. This paper considers new methods in modelling and understanding this potentially complex relationship.

Earlier work on the joint distribution of income and wealth using LWS data (Luxembourg Wealth Study Database (LWS), 2014) used largely descriptive, non-parametric methods. In

\footnotetext{
${ }^{1}$ Reliable, internationally comparable household- or individual-level data on wealth, asset holdings and debt remain limited, with only a few exceptions. The Luxembourg Wealth Study is one of the main sources of cross-nationally comparable data, covering both North American and European countries. The Household Finance and Consumption Survey (HFCS) has recently been made available for euro-zone countries. The SHARE (Survey of Health, Ageing and Retirement in Europe) has been collected for individuals 50 years and older in up to twenty countries.
} 
this paper, apart from describing this relationship, we would like to extend the analysis and ask additional counterfactual questions. For example, how would social inequality change if the relationship between income and wealth in, say, Germany, were more like that of the United States, but the marginal distributions were unchanged? Specifically, we want to compare overall inequality of income and wealth across countries and to examine if country differences are driven by differences in the association between income and wealth, or by differences in the marginal distributions. In our view, the most straightforward way to attain this goal is to work with parametric methods.

The contribution of this paper is to elaborate new methods of inequality analysis in the joint distribution of income and wealth, and to illustrate this approach using data for five OECD countries. We develop and fit a simple yet flexible parametric model for the bivariate distribution. The model handles the specificity of the distribution of wealth, in particular the presence of zero and negative values. We study the joint distribution of income and wealth by separately estimating the univariate marginal distribution models for income and for wealth, and by estimating the parametric copula functions to capture the dependence between income and wealth (Genest and McKay, 1986, Trivedi and Zimmer, 2007). Combining estimates for the marginal distributions and the copula provides flexible estimates of the joint distribution of income and wealth. This approach has the advantage of separating the problems of estimation of marginal distributions and the dependence structure between the two variates.

Endowed with parametric estimates of the joint distribution of income and wealth for five OECD countries, we use our model to compare the degree of dependence between the two variables in different countries. We design a straightforward counterfactual analysis to assess the implications of variations in the dependence parameter on a bivariate version of the Gini coefficient proposed by Koshevoy and Mosler (1997): we evaluate this implication by calculating what would happen in country $\mathrm{X}$ if it had the dependence structure of income and wealth as in country Y. We find that cross-country variations in the association parameter account for only a small fraction of cross-country differences in the bivariate Gini. The index appears primarily driven by differences in the inequality of the net worth distributions. Thus, the way people are able to accumulate wealth matters most for the joint inequality of income and wealth and most cross-country differences in the bivariate inequality stem from these factors.

We describe the datasets used and provide a preliminary inspection of the data in Section 2. 
In Section 3, we present the parametric model for the joint distribution of income and wealth. Estimation results and analysis of the bivariate Gini coefficient are presented in Section 4. Section 5 concludes.

\section{Data and preliminary inspection}

We analyze and compare overall inequality in the distribution of income and wealth in five rich countries using household survey data: a North American country-the United States-and four European countries with varying institutional and welfare regimes: Germany, Italy, Luxembourg and Spain. Our choice of countries is governed by data availability and timeliness. This group of countries also covers different 'equity cultures'. The data for the United States come from the 2007 Survey of Consumer Finances (SCF), for Italy the 2007 Survey of Household Income and Wealth (SHIW), for Germany the 2007 wealth module of the Socio-Economic Panel (SOEP), for Luxembourg from the 2007 wealth module of the PSELL-3/EU-SILC and for Spain the 2008 Spanish Survey of Household Finances (EFF); see Table 1.

Table 1: Data description

\begin{tabular}{lccccc}
\hline Country & Year & Survey & Type & Over-sampling & Unit of Analysis \\
\hline Germany & 2007 & Socio-Economic Panel & Wealth module & wealthy & household \\
Italy & 2008 & Survey of Household Income and Wealth & Wealth survey & & household \\
Luxembourg & 2007 & PSELL-3/ EU-SILC & Wealth module & & household \\
Spain & 2008 & Survey of Household Finances & Wealth survey & & household \\
United States & 2007 & Suvey of Consumer Finances & Wealth survey & wealthy & household \\
\hline
\end{tabular}

All datasets contain detailed information on multiple income sources and financial, nonfinancial assets and debts aggregated at the household level. On the basis of this information, we use the conceptual framework developed by the Luxembourg Wealth Study (LWS) for creating harmonized variables of total wealth and income (Sierminska et al., 2006). The goal of LWS is to provide users, to the extent possible, with comparable variables through ex-post harmonization of data collected independently in separate surveys. In order to achieve this, a thorough examination of each of the wealth and income components collected in the different surveys has been performed to identify the most comparable aggregated data from which a measure of household net worth—-total assets minus total liabilities—is derived. Table 2 shows the composition of our LWS measure of net worth for each of the five datasets: we are able to obtain an aggregate measure composed of financial assets, principal residence and investment 
real estate from which we subtract total debt, which comprises mortgages and non-housing debt.

Thus, in terms of components, we have a comparable measure of net worth, although not all comparability issues are necessarily solved. First, the way the components of net worth have been collected may still vary across countries and may possibly still affect the comparability of the aggregate measures. Note also that non-housing debt is not recorded in Luxembourg and that deposit accounts are collected together with risky assets in Germany, features that both will lead to peculiarities in the data, as we illustrate below. Second, variations in sample design, data collection mode and survey collection goals cannot easily be addressed and harmonized. In the U.S., Italy and Spain, the surveys have been designed explicitly for collecting wealth and income information, while in Luxembourg and Germany, special modules have been added to existing general purpose household panel surveys. Oversampling of the very wealthy has taken place in the U.S. and Germany, while no such feature has been put in place in the other countries. As we show below, wealth inequality reveals higher in these two countries, possibly as a consequence of the care that has been taken to collect data on the most wealthy households. Despite these potential issues that one must bear in mind, LWS data constructs remain a useful source for comparative analysis in that they are well documented (Sierminska et al., 2006) and they have been used extensively in comparative research, including by the OECD (Jäntti et al., 2008, 2013, Sierminska et al., 2013).

Table 2: Overview of wealth portfolio components comprising net worth across the sample surveys.

\begin{tabular}{|c|c|c|c|c|c|c|}
\hline Components & & US & Germany & Italy & Luxembourg & Spain \\
\hline \multirow[t]{3}{*}{ Financial Assets } & & sum & $\mathrm{X}$ & sum & X (banded data) & sum \\
\hline & Deposit accounts & $\mathrm{X}$ & & $\mathrm{X}$ & & $\mathrm{X}$ \\
\hline & Risky assets & $X$ & & $\mathrm{X}$ & & $X$ \\
\hline \multicolumn{2}{|c|}{ Principal residence: current value of own home } & $\mathrm{X}$ & $X$ & $\mathrm{X}$ & $\mathrm{X}$ & $\mathrm{X}$ \\
\hline \multicolumn{2}{|c|}{ Real estate investment } & $\mathrm{X}$ & $\mathrm{X}$ & $\mathrm{X}$ & $X$ (net of mortgages) & $\mathrm{X}$ \\
\hline \multicolumn{2}{|c|}{ Total Debt } & sum & sum & sum & sum & sum \\
\hline \multirow[t]{3}{*}{ Total Mortgage } & & sum & sum & $\mathrm{X}$ & & sum \\
\hline & Mortgage on main home & $\mathrm{X}$ & $\mathrm{X}$ & & $\mathrm{X}$ & $\mathrm{X}$ \\
\hline & Other mortgages & $\mathrm{X}$ & $X$ & & & $X$ \\
\hline Non-housing debt & & $X$ & $X$ & $\mathrm{X}$ & & $\mathrm{X}$ \\
\hline
\end{tabular}
Source: 2007 SCF, 2007 SOEP, 2008 SHIW, 2007 PSELL3 and 2008 EFF

Note: Net worth is the sum of Financial Assets, Principal Residence and Investment Real Estate less Total Debt. ' $\mathrm{X}$ ' indicates that information is collected directly as an aggregate, 'sum' indicates that it is derived as the sum of the more detailed components. 
Our unit of analysis is the household. ${ }^{2}$ Sample sizes range from 3,651 observations in Luxembourg to 10,907 in Germany (Table 3). The variable total disposable household income is created by aggregating income sources from all members and deducting taxes. This is done for all countries except Spain, where only gross income is available. ${ }^{3}$ The variable net worth is similarly constructed by adding up available comparable asset categories and deducting debts from all household members, as we explained above. All values are expressed in 2009 US dollars. ${ }^{4}$ We do not apply equivalence scales as the issue of selecting a relevant equivalence scale for wealth is largely unsettled. ${ }^{5}$ Sample weights are used to compute all statistics and model parameters reported in the paper.

Figure 1 shows (adaptive) kernel density estimates of the marginal distributions of income and wealth calculated from our data. To help visualize the density at small and negative values, the $x$-axis is scaled by an inverse hyperbolic sine transformation. While income distributions have broadly similar shapes in the five countries, the wealth distributions exhibit substantially more variation across countries. The wealth distribution is typically bimodal with a first mode at zero ${ }^{6}$ and is more stretched out over positive values, thereby exhibiting more inequality.

The graphical association of income and wealth is presented in Figure 2, which shows a relative quantile-difference plot. ${ }^{7}$ At the bottom of the distribution, we find wealth quantiles to be below the corresponding income quantiles with wide cross-country variation. The equality between income and wealth levels occurs at the 25th percentile except for Spain (20th percentile) and Germany (50th percentile). Above the 25th percentile, the slope is positive and it is followed by a steep increase for the highest percentiles. The variation of slopes indicates that the association between income and wealth varies across countries as income accumulates into different levels of wealth throughout the distribution.

\footnotetext{
${ }^{2} \mathrm{~A}$ household is defined as including all persons living together in the same dwelling. Sharing expenses is an additional requirement in Italy and the United States.

${ }^{3}$ While we do not adjust for negative data on wealth, we delete observations with income less than or equal to zero as these are not considered in our income distribution model. They only represent a tiny fraction of our samples.

${ }^{4}$ We use the national price deflators for personal consumption to express currencies in 2009 prices and then convert them to international dollars using PPPs for personal consumption (OECD 2011).

${ }^{5}$ See, e.g., the discussions in Bover (2010) or Jäntti et al. (2013).

${ }^{6}$ Note that a spike at exactly zero tends to be smeared out over small values around zero by kernel density estimators. See Table 3 for the share of exact zeros in each country.

${ }^{7} \mathrm{~A}$ relative quantile-difference plot shows the difference between the values of a variable at each percentile of its distribution and the corresponding values of another distribution, as a percent of the values for one of the distributions (Kennickell, 2009).
} 
When taking a detailed look at the data, we find that the fraction of negative and zero net worth in our samples varies substantially across countries. Table 3 indicates that about $33 \%$ of the sample in Germany has zero or negative net worth, but only about 5\% in Spain, 9\% in the U.S., $11 \%$ in Italy and $12 \%$ in Luxembourg. This is driven, at least partly, by discrepancies in data collection since the five surveys differ in the collection of assets and debts. For example, the high share of zeros in Germany is likely related to the fact that the lowest amounts of financial assets are disregarded; the fact that no negative net worth is recorded in Luxembourg is likely due to the fact that only home-related debt is recorded. In any case, these values clearly illustrate the necessity of a modelling strategy to deal with such non-positive observations.

The descriptive statistics reported in Table 3 show that the average level of wealth is much higher than the average level of annual income. The ratio of means of wealth and income varies substantially across countries: from about 4 in Germany to almost 10 in Luxembourg (ratios of medians range from 0.8 in Germany to 8.1 in Luxembourg and Spain). ${ }^{8}$ Mean wealth holdings are the largest in Luxembourg and the U.S. Median wealth holdings in Luxembourg are particularly striking in comparison to other countries.

To gain insight into the degree of dependence between wealth and income in our countries, Table 3 reports the proportion of observations found in the bottom and top quintile groups of both the income and wealth distributions. If the ranks in income and wealth were perfectly correlated, we would observe $20 \%$ of the samples in each of the groups. If, on the other hand, there were zero correlation in ranks, we would observe about $4 \%$ of the samples in each of the quintile group cells. A negative correlation could lead, at the extreme, to no data in these cells. In most countries, 8 to 11 percent of the sample can be found in each of the cells. The exception is Spain, where we find $5 \%$ of the sample in the lowest fifth of both income and wealth and $7 \%$ in the top fifths.

There are several reasons to be interested in the association of income and wealth. For instance, a greater positive association may suggest households are less able to rely on savings to smooth consumption. The association also speaks to the extent that income taxation also targets wealth holdings. (We shall return to this issue when discussing the copula estimates below.)

\footnotetext{
${ }^{8}$ Note that unlike for the other countries for Spain we observe gross income only, thereby inflating values of income compared to other countries.
} 
Table 3: Sample descriptives

\begin{tabular}{lccccc}
\hline & US & Germany & Italy & Luxembourg & Spain \\
\hline Observations & 4,232 & 10,907 & 7,899 & 3,651 & 5,013 \\
\hline NW>0 & 0.913 & 0.670 & 0.892 & 0.882 & 0.944 \\
NW=0 & 0.020 & 0.205 & 0.070 & 0.115 & 0.009 \\
NW<0 & 0.067 & 0.124 & 0.038 & 0.003 & 0.047 \\
\hline Mean & & & & \\
Net worth & 572,015 & 136,472 & 284,394 & 578,364 & 339,744 \\
Income & 68,542 & 33,101 & 37,368 & 59,424 & 34,348 \\
\hline Median & & & & \\
Net worth & 133,900 & 21,739 & 175,976 & 407,088 & 235,330 \\
Income & 40,522 & 27,159 & 30,107 & 50,415 & 29,096 \\
\hline Proportions in quintile groups & \multicolumn{5}{c}{50.15} \\
QI1 \& QW1 & 9.30 & 11.93 & 10.16 & 9.57 & 5.16 \\
QI5 \& QW5 & 11.60 & 8.98 & 11.64 & 8.83 & 7.17 \\
\hline
\end{tabular}

Note: 'QI1 \& QW1' refers to households in both the lowest income and wealth quintile groups 'QI5 \& QW5' refers to households in both the highest income and wealth quintile groups

Table 4 shows additional summary indices of the association between income and net worth in our samples. The Pearson correlation coefficient gives us an indication of the linear relationship between income and wealth. The others—Spearman's $\rho$ and Kendall's Tau—are rank correlation indicators closely connected to the copula dependence parameters. The latter are often preferred to Pearson correlations for non-normal data, since they are less sensitive to outliers which can exert a strong influence on Pearson correlations (Croux and Dehon, 2010). We observe the highest linear correlation between income and wealth in the U.S. (0.61) and Germany (0.59) - the countries that oversampled the wealthy and probably best capture very high wealth. Pearson correlations are low in Luxembourg (0.17) and Spain (0.17). When it comes to rank correlations that are less sensitive to extreme data, the country ranking changes. The highest Spearman correlation is in Italy (0.64), then in the U.S. (0.61), Luxembourg (0.46), Germany (0.41) and Spain (0.26). A similar ranking is obtained for Kendall's Tau. This ordering is different though from what comes out of the proportions of households jointly in the top or bottom quintile groups of income and wealth reported in Table 3.

Overall the results indicate a positive dependence between income and net worth, but that dependence is complex and may not be captured well by single summary indices. The Pearson 
Table 4: Association measures

\begin{tabular}{lccccc}
\hline & US & Germany & Italy & Luxembourg & Spain \\
\hline Pearson correlation & 0.608 & 0.586 & 0.520 & 0.174 & 0.169 \\
Spearman correlation & 0.607 & 0.405 & 0.641 & 0.461 & 0.256 \\
Kendall's Tau & 0.435 & 0.279 & 0.461 & 0.321 & 0.174 \\
\hline
\end{tabular}

correlations in particular appear to be sensitive to high wealth.

\section{A parametric model for the joint distribution of income and wealth}

In this section, we formulate our parametric model for the joint distribution of income and wealth. A strong strand of the income distribution literature is concerned with the specification and estimation of parametric functional forms for income distributions. Parametric models can describe the shape of the income distribution using only a few parameters from which a range of summary measures or Lorenz ordinates can be derived. Comparisons of parameter sets can also be used for stochastic dominance analysis. Income distribution models are now largely settled, with the log-normal, Singh-Maddala, Dagum, and GB2 distributions being leading examples, but such models cannot generally be applied to wealth data due to its special characteristics. The presence of negative and zero values of net worth (when debts exceed the value of assets) invalidates the parametric statistical models typically used to describe income distributions, as virtually all such models are defined for positive data only (Dagum, 1990). Parametric models of wealth distributions are therefore much less common.

As mentioned in the Introduction, our approach to modelling the bivariate distribution of income and wealth involves specifying separate models for the marginal distributions and for dependence parameter(s). This modelling strategy for the dependence between the two relies on Sklar's (1959) theorem, which shows that (continuous) multivariate distributions can be uniquely expressed as a function of a copula and univariate marginal distributions,

$$
F(y, w)=C\left(F_{Y}(y), F_{W}(w)\right)
$$

where $F$ is the joint cumulative distribution function of income and wealth, $F_{Y}$ and $F_{W}$ denote 
the marginal cumulative distribution functions of income $(Y)$ and wealth $(W)$, and $C$ is a copula. We model $F$ parametrically by specifying separate models for each of $F_{Y}, F_{W}$ and $C$. We describe our specifications for each of the three components in turn.

\section{The marginal distribution of income}

Specifying a parametric model for the marginal distribution of income is unproblematic. A variety of specifications are available; see, for example, McDonald (1984). We follow common practice and rely on a Singh-Maddala specification (Singh and Maddala, 1976). The SinghMaddala distribution is a three-parameter model for unimodal distributions allowing varying degrees of skewness and kurtosis and dealing with the heavy tails typical of income and earnings distributions. It is used, e.g., in Brachmann et al. (1996) and Biewen and Jenkins (2005) to model income distributions. The cumulative distribution function is

$$
F_{Y}(y)=\operatorname{SM}(y ; a, b, q)=1-\left[1+\left(\frac{y}{b}\right)^{a}\right]^{-q}
$$

where $b>0$ is a scale parameter, $q>0$ is a shape parameter for the upper tail, $a>0$ is a shape parameter affecting both tails (Kleiber and Kotz, 2003). As we show below, the Singh-Maddala model provides a very good fit to our income data.

\section{The marginal distribution of wealth}

Specifying the marginal distribution of wealth is more difficult. Although it is customary to analyze specific components of wealth, such as assets or debts, the literature on wealth inequality most often focuses on the concept of net worth, defined as the value of total assets (financial and non-financial) minus total debts. Consequently, it is conceptually possible and empirically relatively common to observe data with zero or negative net worth. Our parametric model must therefore be able to accommodate negative data. This rules out virtually all specifications typically used for modeling income distributions, since these size distributions have positive density only over the positive halfline $R_{+}$.

To accommodate zero and negative data, we follow Dagum (1990) (also see Jenkins and Jäntti, 2005) and use a finite mixture model where negative, zero and positive data are modeled separately with an exponential distribution (negatives), a point-mass at zero and a Singh- 
Maddala distribution (positives, respectively:

$$
F_{W}(w)= \begin{cases}\pi_{1} \exp (\theta w) & \text { if } w<0 \\ \pi_{1}+\pi_{2} & \text { if } w=0 \\ \pi_{1}+\pi_{2}+\left(1-\pi_{1}-\pi_{2}\right) \operatorname{SM}(w ; \alpha, \beta, \gamma) & \text { if } w>0\end{cases}
$$

where $\pi_{1}$ and $\pi_{2}$ are the shares of negatives and zeros in the data, $\alpha, \beta$ and $\gamma$ are interpreted as above and $\theta>0$ is shape parameter for the negative distribution with lower values for $\theta>0$ leading to thicker negative tail. We depart from Dagum's (1990) original model by using a Singh-Maddala distribution for positive data instead of a Dagum type I distribution (the two distributions have similar shapes). ${ }^{9}$

\section{Copula function specification}

The third ingredient of the specification of the joint distribution is the shape of the copula $C$ which captures the rank-order association between the two marginal distributions. In the absence of clear guidance from earlier research regarding the most appropriate specification for the copula in this context, we experimented with several alternative specifications: the Plackett copula, the Clayton and rotated Clayton copulas, and a more flexible 3-parameter specification mixing the Clayton and rotated Clayton copulas (See Trivedi and Zimmer (2007) for a review of different copula functions and Chau (2010) on mixing copulas). The first choice revealed most satisfactory in our application: the copula parameters for the last two models generally could not be estimated reliably due to convergence problems and the Plackett copula resulted in a better fit to the rank dependence of income and wealth in our datasets than the Clayton copula. ${ }^{10}$

The specification of the Plackett copula (Plackett, 1965) is:

$$
C(u, v ; \tau)=\frac{\left((1+(\tau-1)(u+v))-\sqrt{\left.(1+(\tau-1)(u+v))^{2}\right)-4 u v(\tau-1) \tau}\right)}{2(\tau-1)}
$$

where $\tau \in[0, \infty) \backslash\{1\}$ is a dependence parameter. $\tau>1$ leads to positive dependence

\footnotetext{
${ }^{9}$ For coherence with the income distribution we use the Singh-Maddala distribution.

${ }^{10}$ The Plackett copula exhibits symmetric upper-tail and lower-tail dependence whereas the Clayton copula exhibits stronger lower-tail dependence. This may explain the differences in goodness of fit between these two familiar copula specifications.
} 
and the higher $\tau$, the higher is the dependence. Independence is obtained at $\tau=1$. The Plackett copula exhibits symmetric upper-tail and lower-tail dependence. The parameter of the Plackett copula can be related to Spearman's rank correlation coefficient as follows: $S=$ $((\tau+1) /(\tau-1))-\left(2 \log (\tau) \tau /(\tau-1)^{2}\right)$, but there is no simple closed-form expression for Kendall's Tau in terms of the Plackett copula parameter. ${ }^{11}$ It has been used by, e.g., Bonhomme and Robin (2009) in a model of earnings dynamics.

\section{Estimation}

Parameters of the three components $F_{Y}, F_{W}$ and $C$ can be estimated separately. In this paper, all parameters for $F_{Y}$ and $F_{W}$ were first estimated by conventional maximum likelihood using the built-in Newton-Raphson optimizer of Stata ${ }^{\mathrm{TM}}$ (StataCorp, 2011). ${ }^{12}$ Maximum likelihood estimation of the copula parameter is done in a second stage based on the sample values of $\left(\hat{F}_{Y}\left(y_{i}\right), \hat{F}_{W}\left(w_{i}\right)\right)$ with $\hat{F}_{Y}$ and $\hat{F}_{W}$ based on the first stage parameter estimates.

\section{Estimation results}

We now report results from estimating our parametric model for the joint distribution of income and wealth. We first briefly report the detailed parameter estimates and assess the goodness of fit of the models. We then present inequality indicators derived from the model parameters, along with counterfactual constructs to quantify the role played by cross-national differences in association parameters on differences in bivariate inequality.

Parameter estimates for the proposed model estimated for each of the five countries are reported in Table 5. The top panel shows parameter estimates for the Singh-Maddala distribution of income; the middle panel shows parameters for the mixture model of net worth, namely the share of negative and zero data, and the four distribution parameters; the bottom panel shows estimates of the two copula function parameters considered. Since we could not estimate reliably the model for negative wealth in Luxembourg given the small number of observations reporting negative net worth-we discarded these few observations and worked with a model

\footnotetext{
${ }^{11}$ See e.g. Agresti (2010) for a discussion of Spearman's correlation and Kendall's Tau as measures of rank dependence.

${ }^{12}$ Example of Stata code for estimating the wealth distribution parameters is available in Jenkins and Jäntti (2005).
} 
with just two components (positives and zeros) in this country.

The similarity of the income distributions across countries is reflected in the relative similarity of coefficients of the Singh-Maddala distribution. ${ }^{13}$ Wealth distribution parameters, on the other hand, vary substantially, in line with differences in the shape of the wealth distributions across countries. For example, for data with positive wealth, the scale parameter $(\beta)$ shows large variations with much higher levels of wealth in Luxembourg. The shape parameters, in turn, suggest relatively low inequality in Luxembourg.

In line with the rank correlation statistics reported in Table 4, our copula function parameter estimates split our five countries into two groups: the U.S. and Italy, on the one hand, which exhibits strong dependence between income and wealth (high copula parameters) and on the other hand, Luxembourg, Germany and Spain, with a much smaller level of (positive) dependence. Why, exactly, we find these differences is hard to tell. One possible explanation could be differences in the patterns of home ownership and income. The interaction of institutional differences with the full joint distribution remains a topic for future work.

The overall goodness of fit of our model can be gauged by comparing summary statistics derived from the model parameters to the statistics computed from the raw data. Since no closed-form expression exists for deriving the various summary measures from the model parameters, our estimation is based on Monte Carlo sampling on the basis of the models and estimated parameters. We simulate pseudo-samples of 3000 income and wealth pairs for each country based on the inverse sampling method: we first draw 3000 correlated pairs of uniformly distributed variates $(u, v)$ where the correlation is determined by the copula parameter (Nelsen, 2006) and we then generate the wealth and income pairs as $\left(F_{Y}^{-1}(u), F_{W}^{-1}(v)\right)$, that is the $u$-th and $v$-th theoretical quantiles implied by the parameter estimates of the marginal distributions. Model-based summary statistics are finally obtained based on standard calculations on the pseudo-samples.

Figures 3 and 4 show observed and model-based predictions of the income quantile function and of the wealth quantile function. Figure 5 shows observed and model-based predictions of the copula $\mathrm{CDF}$, namely the joint distribution function of household ranks in the distribution income and wealth (the darker the color, the higher the value of the CDF, with contour lines

\footnotetext{
${ }^{13}$ The difference in parameter estimates across countries is large compared to their standard errors, suggesting that distributions are different across countries from a statistical point of view.
} 
Table 5: Parameter estimates (standard errors in brackets)

\begin{tabular}{|c|c|c|c|c|c|}
\hline & USA & Germany & Italy & Lux'g & Spain \\
\hline \multicolumn{6}{|c|}{ Income distribution } \\
\hline \multirow[t]{2}{*}{$a$} & 1.99 & 1.89 & 2.53 & 2.77 & 1.96 \\
\hline & $(0.04)$ & $(0.02)$ & $(0.04)$ & $(0.07)$ & $(0.04)$ \\
\hline \multirow[t]{2}{*}{$b$} & 41,059 & 49,173 & 34,022 & 58,197 & 46,377 \\
\hline & $(1,695)$ & $(1,803)$ & $(1,010)$ & $(2,291)$ & $(2,680)$ \\
\hline \multirow{2}{*}{$q$} & 1.02 & 2.50 & 1.22 & 1.32 & 2.15 \\
\hline & $(0.05)$ & $(0.12)$ & $(0.06)$ & $(0.09)$ & $(0.17)$ \\
\hline \multicolumn{6}{|c|}{ Wealth distribution } \\
\hline \multirow[t]{2}{*}{$\pi_{1}$} & 0.067 & 0.123 & 0.038 & 0.000 & 0.047 \\
\hline & $(0.004)$ & $(0.005)$ & $(0.003)$ & () & $(0.005)$ \\
\hline \multirow[t]{2}{*}{$\pi_{2}$} & 0.020 & 0.208 & 0.070 & 0.116 & 0.009 \\
\hline & $(0.003)$ & $(0.005)$ & $(0.004)$ & $(0.008)$ & $(0.002)$ \\
\hline \multirow[t]{2}{*}{$\theta\left(\times 10^{7}\right)$} & 544 & 327 & 1193 & & 531 \\
\hline & $(37)$ & (9) & (69) & () & (43) \\
\hline \multirow[t]{2}{*}{$\alpha$} & 0.73 & 0.73 & 0.84 & 0.98 & 0.97 \\
\hline & $(0.01)$ & $(0.01)$ & $(0.01)$ & $(0.02)$ & $(0.01)$ \\
\hline \multirow[t]{2}{*}{$\beta$} & 756,007 & $3,519,022$ & $5,431,515$ & $4,999,554$ & $3,358,732$ \\
\hline & $(123,627)$ & $(866,305)$ & $(1,268,135)$ & $(944,732)$ & $(603,599)$ \\
\hline \multirow[t]{2}{*}{$\gamma$} & 2.63 & 10.38 & 12.94 & 8.69 & 10.04 \\
\hline & $(0.22)$ & $(1.55)$ & $(2.14)$ & $(1.28)$ & $(1.42)$ \\
\hline \multicolumn{6}{|c|}{ Copula parameters } \\
\hline \multirow[t]{2}{*}{ Plackett $\tau$} & 7.66 & 3.78 & 7.90 & 4.45 & 2.18 \\
\hline & $(0.040)$ & $(0.020)$ & $(0.040)$ & $(0.070)$ & $(0.040)$ \\
\hline
\end{tabular}


showing 20 isoquants for values of $0.01,0.05,0.10$ to 0.95 ).

Finally, Table 6 reports on a range of summary statistics. The parametric fit of the income distribution is very good in all countries. The fit of the wealth distribution is more problematic. For the U.S., the model fits well the shape of the empirical wealth distribution, except for the top wealth quantiles. This leads to some underestimation by the model of both mean wealth and its dispersion compared to the empirical estimates. In the other four countries, on the other hand, mean wealth and the Gini are more closely approximated by the model, but larger deviations between observed and predicted quantiles are present in the middle of the distribution. The empirical wealth quantile functions in those four countries show somewhat irregular patterns (especially in Luxembourg), with non-monotonic increases in the quantiles in the middle of the distribution. We are unable to detect whether this is a 'true' feature of wealth holdings in those countries or an issue connected to data collection, but such patterns are difficult to fit closely with a parsimonious parametric model. Reassuringly, Kendall's Tau and Spearman correlations are closely approximated by the models. The Pearson correlations are, however, poorly predicted from the model parameters. We suspect this is related to both the discrepancy between the model and the empirical estimates for the wealth distributionremember the Pearson correlation's sensitivity to extreme data in marginal distributions-and the fact that our simple, single parameter copula function approximates a potentially complex empirical dependence structure.

We now exploit our models to separate out the contributions of the dependence parameter and of the marginal distributions in accounting for cross-national differences in inequality. Table 7 first reports Gini coefficient estimates for the (univariate) distributions of income and wealth derived from our model parameters (using the Monte Carlo simulation described above). It is clear that wealth is substantially more unequally distributed than income in each country. If we take Spain and Germany out of the picture for a moment, we see that the inequality ranking of wealth follows that of income. ${ }^{14}$

To capture inequality in the joint distribution of income and wealth, we rely on the bivariate Gini coefficient of Koshevoy and Mosler (1997). The Koshevoy and Mosler (1997) bivariate Gini index is an extension of the univariate Gini based on a bivariate, Euclidian distance-based

\footnotetext{
${ }^{14}$ Spain is slightly different because we measure gross income only. Germany does not capture very well the bottom of the distribution and there are many zeroes.
} 
Table 6: Empirical vs. model-based estimates

\begin{tabular}{llllll}
\hline & USA & Germany & Italy & Lux'g & Spain \\
\hline Empirical estimates: & & & & & \\
Mean income & 68,752 & 32,833 & 37,368 & 59,266 & 34,348 \\
Mean wealth & 572,845 & 135,664 & 284,394 & 575,854 & 339,744 \\
Gini income & 0.538 & 0.374 & 0.354 & 0.316 & 0.376 \\
Gini wealth & 0.809 & 0.807 & 0.611 & 0.578 & 0.544 \\
Pearson correlation & 0.641 & 0.578 & 0.520 & 0.175 & 0.169 \\
Spearman correlation & 0.602 & 0.399 & 0.642 & 0.461 & 0.257 \\
Kendall's Tau & 0.431 & 0.274 & 0.462 & 0.321 & 0.174 \\
\hline Model-based estimates: & & & & & \\
Mean income & 61,497 & 32,323 & 37,298 & 59,106 & 34,241 \\
Mean wealth & 482,151 & 130,372 & 278,726 & 546,841 & 329,575 \\
Gini income & 0.485 & 0.371 & 0.354 & 0.315 & 0.373 \\
Gini wealth & 0.774 & 0.809 & 0.628 & 0.591 & 0.565 \\
Pearson correlation & 0.230 & 0.269 & 0.439 & 0.343 & 0.182 \\
Spearman correlation & 0.597 & 0.416 & 0.604 & 0.463 & 0.253 \\
Kendall's Tau & 0.428 & 0.285 & 0.433 & 0.321 & 0.170 \\
\hline
\end{tabular}

Note: Empirical estimates are derived directly from the raw samples. Model-based estimates are derived from the model parameter estimates (by simulation). All estimates are based on a single set of multiply imputed data and may therefore differ marginally from estimates reported in Section 2 (Table 4) for the US and Germany.

Table 7: Gini coefficient estimates (model-based)

\begin{tabular}{lccccc}
\hline \multicolumn{1}{c}{ USA } & Germany & Italy & Lux'g & Spain \\
\hline Gini coefficients & \multicolumn{5}{l}{} \\
Income & 0.485 & 0.371 & 0.354 & 0.315 & 0.373 \\
Wealth & 0.774 & 0.809 & 0.628 & 0.591 & 0.565 \\
Joint & 0.747 & 0.702 & 0.560 & 0.522 & 0.540 \\
\hline Counterfactual joint Gini coefficients (fix US copula) \\
Joint & 0.747 & 0.692 & 0.561 & 0.516 & 0.526 \\
\hline Counterfactual joint Gini coefficients (fix US wealth margin) \\
Joint & 0.747 & 0.692 & 0.675 & 0.663 & 0.700 \\
\hline
\end{tabular}


extension of the Gini Mean Deviation:

$$
G_{2}=\frac{1}{4 N^{2}} \sum_{i=1}^{N} \sum_{j=1}^{N}\left(\left(\frac{y_{i}}{\mu_{y}}-\frac{y_{j}}{\mu_{y}}\right)^{2}+\left(\frac{w_{i}}{\mu_{w}}-\frac{w_{j}}{\mu_{w}}\right)^{2}\right)^{\frac{1}{2}}
$$

Compare this with the univariate version of the Gini coefficient:

$$
G_{1}=\frac{1}{2 N^{2}} \sum_{i=1}^{N} \sum_{j=1}^{N}\left|\frac{y_{i}}{\mu_{y}}-\frac{y_{j}}{\mu_{y}}\right|
$$

$G_{1}$ can be interpreted in terms of the average absolute difference (or 'distance') between any two incomes drawn from a univariate distribution (normalized by the mean). The bivariate $G_{2}$ can be interpreted similarly in terms of the average Euclidian distance between any two income-wealth pairs drawn from the joint distribution (normalized by their respective means). The bivariate Gini is determined by the degree of inequality in the two marginal distributions as well as by the association among the two covariates. Our focus remains on Gini coefficients because, unlike many inequality measures, they remain defined for negative and zero net worth—an essential feature for measuring wealth inequality (Jenkins and Jäntti, 2005). ${ }^{15}$

Recall that our main objective is to assess the overall inequality of the distribution of income and wealth. To this end, Table 7 reports estimates of the bivariate Gini. While levels of bivariate inequality differ according to the specification used, the ordering of countries is preserved. In all cases, it appears that inequality in wealth remains a key determinant of overall inequality: bivariate Ginis are close to univariate Ginis for wealth. Notice, however, that because the association between income and wealth is not perfectly positive, the bivariate takes on a value between the two marginal Ginis.

In order to understand the relative role of the association between income and wealth, as captured by the copula, and the marginal distributions, Table 7 also reports two sets of counterfactual estimates of the bivariate Ginis. The first set is obtained by fixing the U.S. dependence parameter and applying it to all countries' marginal distributions. The indices obtained therefore give us the value of the bivariate Gini which would be observed in the different countries if the association between income and wealth were as high as in the U.S. Comparing

\footnotetext{
${ }^{15}$ Arguably, more sophisticated measures of multi-dimensional inequality or poverty could be considered for more in-depth analysis (Lugo, 2005). The presence of negative net worth would however remain a critical constraint on the choice of relevant multidimensional inequality measures, as it is in the univariate case.
} 
the counterfactual indices with the previous estimates gives us an indication of the impact of cross-national differences in the association parameter on overall inequality differences. ${ }^{16}$

Our estimates suggest that swapping the dependence parameter would only have a small impact on bivariate inequality. This simple mechanical exercise demonstrates that, despite the large variations across countries in the dependence between income and wealth, these differences are of secondary importance in overall, bivariate inequality. To benchmark this effect, the second set of counterfactuals shows what the bivariate Ginis would be if the parameters of the marginal wealth distribution were fixed at the level of the U.S. For Germany-another country with high wealth inequality - the impact of the swap is very small, but Spain, Luxembourg and Italy would see bivariate inequality grow by about twenty percent if their distribution of wealth were the same as in the United States (holding constant their income distribution and their dependence parameter). The impact of cross-national differences in dependence is, by comparison, very small.

Given that inequality of net worth is high relative to that of income, it may not be surprising that the differences in dependence account for little in the overall inequality of income and wealth. Indeed, a case might be made that decisions about taxation can be made largely based on marginal distributions alone. One may also question the value of examining bivariate Gini coefficients - differences in net worth inequality seem to dominate in those as well. However, we still think it is useful to explore these issues; after all, it is through the analysis of inequality of the joint distribution we discovered that net worth inequality dominates the picture.

\section{Concluding remarks}

Relatively little is known about the empirical relationship between income and wealth and the overall inequality in the joint distribution of the two. In this paper, we set out to provide a new, parametric framework for analyzing this relationship. A better understanding of this relationship should prove useful in spheres such as the design of taxation and redistribution policies and better identification and targeting of vulnerable population groups. A framework

\footnotetext{
${ }^{16}$ Calculations are again based on Monte Carlo sampling: to obtain counterfactual indices, a new set of pseudosamples are drawn where the parameter of the U.S. copula functions are used to generate the correlated pairs of uniformly distributed variates and parameters of each of the countrys' marginal distributions are used to convert the uniform variates into income and wealth pseudo-sample values.
} 
for modelling this complex relationship can therefore provide a useful tool for examining or simulating the broader distributional implications of potential policy changes (e.g. wealth taxation).

To achieve our goals, we consider a relatively simple parametric model for the joint distribution of income and wealth. We use this model to examine whether joint income and wealth inequality provides us with a different pattern of social inequality than the traditional income-only approach. Our parameter of focus is the dependence parameter between income and wealth. We use our model to disentangle the relative contribution of cross-national differences in this dependence parameter from cross-national differences in marginal distributions in shaping differences in overall, bivariate inequality. This is done by exploiting the simple structure of our model to generate counterfactual distributions of interest.

The framework offered by the Sklar theorem to build a model for the bivariate distribution is attractive in this context since the marginal distributions of income and wealth have specificities that require differentiated treatment-in particular, the presence of zero and negative net worth. It would therefore be difficult to directly identify a relevant joint distribution. Specification of the copula function for capturing the rank-order association is a key step in the process. We have considered several simple, tractable functions-the Plackett copula being our preferred choice-although these simple functions may not fully capture the complex dependence between income and wealth observed in our samples.

Deriving inequality indicators from the estimated models, we find-unsurprisingly — that Gini coefficients on income are much lower than Gini coefficients on wealth. A bivariate Gini coefficient summarizing inequality in the joint distribution of income and wealth returns intermediate values - with the highest value found in the U.S. The bivariate Gini appears largely driven by inequality in the wealth distribution and differences across countries in the dependence between income and wealth do not appear to be key drivers in international differences in bivariate inequality, but the way people generate their wealth matters.

The variation in the positive association between income and wealth across countries, with Italy and the U.S. standing quite apart from the rest, suggests there may be substantial variation across countries in the ability of households to protect themselves against income shocks by drawing on wealth. This can also be the result of safety nets if low assets is a condition of receiving benefits, as is the case in the U.S. for example. The variation in dependence may 
also be of interest from the perspective of taxation. The more positive the dependence, the better income tax also targets high concentrations of wealth. This also suggest that income taxes could be more progressive in this case. With a low dependence, the case for both income and wealth taxation may be stronger. Low dependence can also be the result of not having asset-based benefits, which would facilitate asset accumulation and savings for "a rainy day" (i.e. income fluctuation). It is also possible that our results are in part accounted for by differences in home ownership patterns across the distribution of income. Such interactions between institutions and the joint distribution of income and wealth are important topics for future research.

Unfortunately, although we have used some of the most comparable sources of wealth and income data available, we can not rule out that part of the differences we find are driven by differences in survey design and implementation. The U.S. and to some extent German data oversample the wealthy, and although we use sample weights, if other countries simply fail to gather wealth information from the wealthy, weights only partly solve this difference. Countryspecific institutions for wealth differ and so will the details of the survey instruments. However, we still believe it is valuable to explore the joint distribution of income and wealth as we do here; with time, it will become more clear what part of the differences across countries are driven by differences in data collection and which represent genuine distributional differences. We have taken the first steps.

\section{References}

Agresti, A. (2010), Analysis of Ordinal Categorical Data, Wiley Series in Probability and Statistics, 2 edn, John Wiley and Sons, Inc.

Biewen, M. and Jenkins, S. P. (2005), 'Accounting for differences in poverty between the USA, Britain and Germany', Empirical Economics 30(2), 331-358.

Bonhomme, S. and Robin, J.-M. (2009), 'Assessing the equalizing force of mobility using short panels: France, 1990-2000', Review of Economic Studies 76(1), 63-92.

Bover, O. (2010), 'Wealth inequality and household structure: U.S. versus Spain', Review of Income and Wealth 56(2), 259-290. 
Brachmann, K., Stich, A. and Trede, M. (1996), 'Evaluating parametric income distribution models', Allgemeines Statistisches Archiv 80, 285-298.

Chau, T. W. (2010), Essays on earnings mobility within and across generations using copula, $\mathrm{PhD}$ thesis, University of Rochester, Dept. of Economics.

URL: http://hdl.handle.net/1802/11125

Croux, C. and Dehon, C. (2010), 'Influence functions of the Spearman and Kendall correlation measures', Statistical Methods \& Applications 19(4), 497-515.

Dagum, C. (1990), A model of net wealth distribution specified for negative, null and positive wealth. A case study: Italy, in C. Dagum and M. Zenga, eds, 'Income and Wealth Distribution, Inequality and Poverty', Springer, Berlin and Heidelberg, pp. 42-56.

Genest, C. and McKay, J. (1986), 'The joy of copulas: Bivariate distributions with uniform marginals', American Statistician 40(4), 280-3.

Jäntti, M., Sierminska, E. and Smeeding, T. (2008), The joint distribution of household income and wealth: Evidence from the Luxembourg Wealth Study, OECD Social Employment and Migration Working Paper 65, OECD, Directorate for Employment, Labour and Social Affairs.

Jäntti, M., Sierminska, E. and Van Kerm, P. (2013), The joint distribution of income and wealth, in J. C. Gornick and M. Jäntti, eds, 'Income inequality. Economic Disparities and the Middle Class in Affluent Countries', Stanford University Press, Stanford, CA, chapter 11, pp. 312-333.

Jenkins, S. P. and Jäntti, M. (2005), Methods for summarizing and comparing wealth distributions, ISER Working Paper 2005-05, Institute for Social and Economic Research, University of Essex, Colchester, UK.

Jenkins, S. P. and Van Kerm, P. (2009), The measurement of economic inequality, in W. Salverda, B. Nolan and T. M. Smeeding, eds, 'Oxford Handbook of Economic Inequality', Oxford University Press, chapter 3.

Kennickell, A. B. (2009), Ponds and streams: wealth and income in the U.S., 1989 to 2007, 
Finance and Economics Discussion Series 2009-13, Board of Governors of the Federal Reserve System (U.S.).

Kleiber, C. and Kotz, S. (2003), Statistical size distributions in Economics and Actuarial Sciences, John Wiley and Sons, Inc., New Jersey.

Koshevoy, G. A. and Mosler, K. (1997), 'Multivariate Gini indices', Journal of Multivariate Analysis 60, 252-276.

Lugo, M. A. (2005), Comparing multidimensional indices of inequality: Methods and application, ECINEQ Working Paper 14, Society for the Study of Economic Inequality.

Luxembourg Wealth Study Database (LWS) (2014), "http://www.lisdatacenter. org (multiple countries; microdata last accessed in july 2014)', Statistical micro-level database. Luxembourg: LIS.

McDonald, J. B. (1984), 'Some generalized functions for the size distribution of income', Econometrica 52(3), 647-663.

Nelsen, R. B. (2006), An introduction to copulas, 2 edn, Springer, New York.

Plackett, R. L. (1965), 'A class of bivariate distributions', Journal of the American Statistical Association 60, 516-522.

Sierminska, E., Brandolini, A. and Smeeding, T. (2006), 'The Luxembourg Wealth Study: A cross-country comparable database for household wealth research', Journal of Economic Inequality 4(3), 375-383.

Sierminska, E., Smeeding, T. and Allegrezza, S. (2013), The distribution of assets and debt, in J. C. Gornick and M. Jäntti, eds, 'Income inequality. Economic Disparities and the Middle Class in Affluent Countries', Stanford University Press, Stanford, CA, chapter 10, pp. 285311.

Singh, S. K. and Maddala, G. S. (1976), 'A function for size distribution of incomes', Econometrica 44(5), 963-970.

Sklar, A. (1959), 'Fonctions de répartition à $n$ dimensions et leurs marges', Publications de l'Institut de Statistique de l'Université de Paris 8, 229-231. 
StataCorp (2011), Stata Statistical Software: Release 12, StataCorp LP, College Station.

Trivedi, P. K. and Zimmer, D. M. (2007), 'Copula modeling: An introduction for practitioners', Foundations and Trends in Econometrics 1(1), 1-111. 


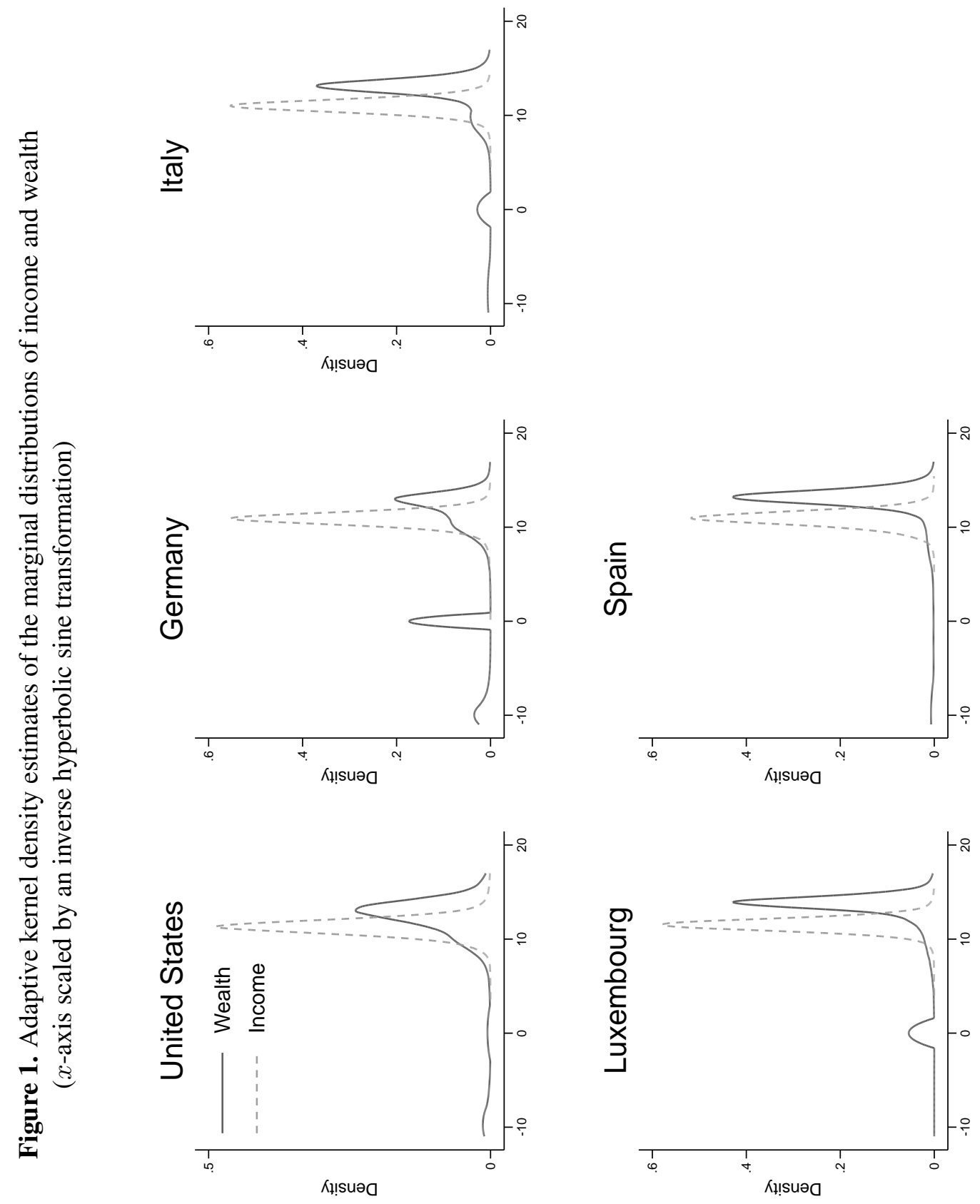




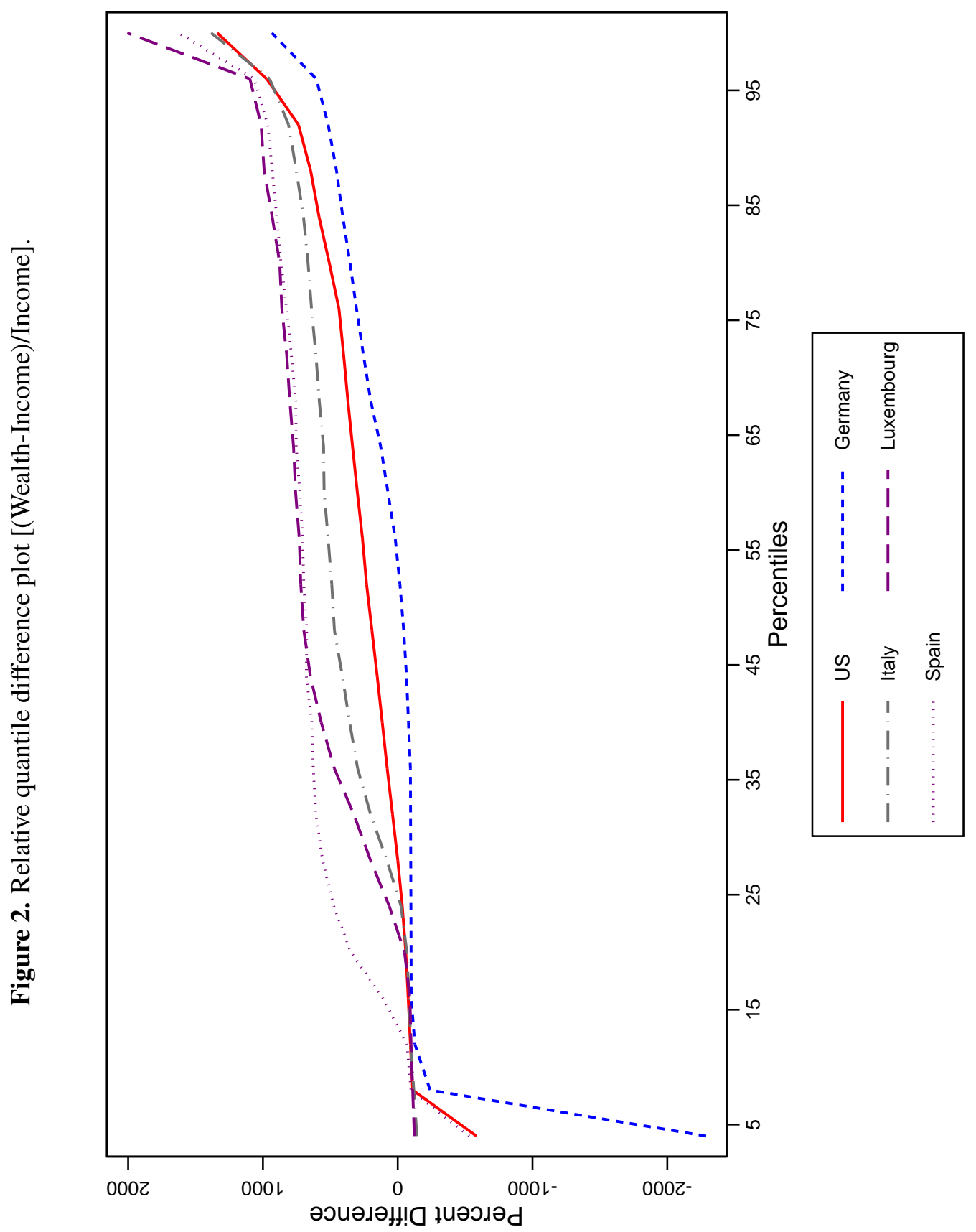




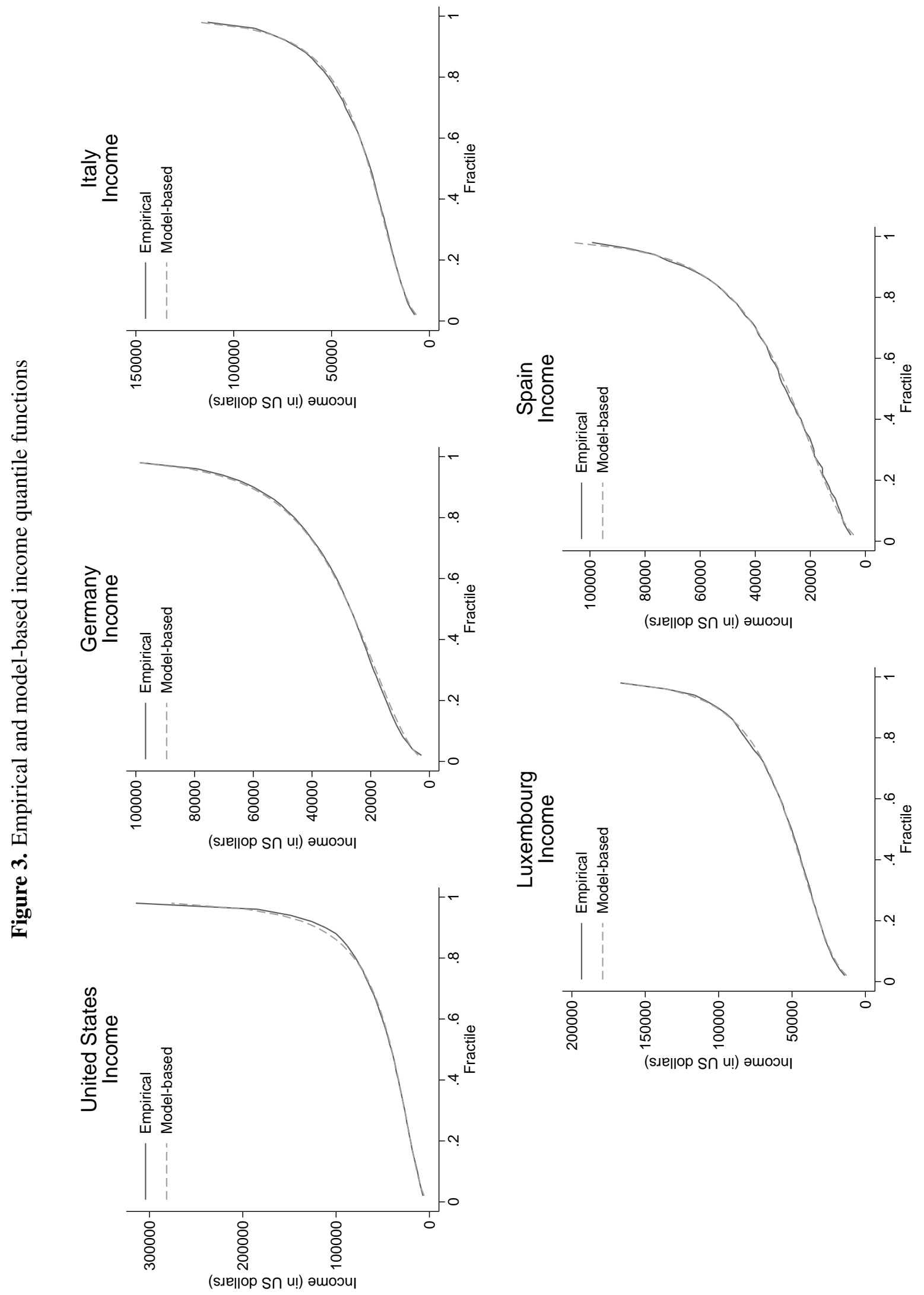




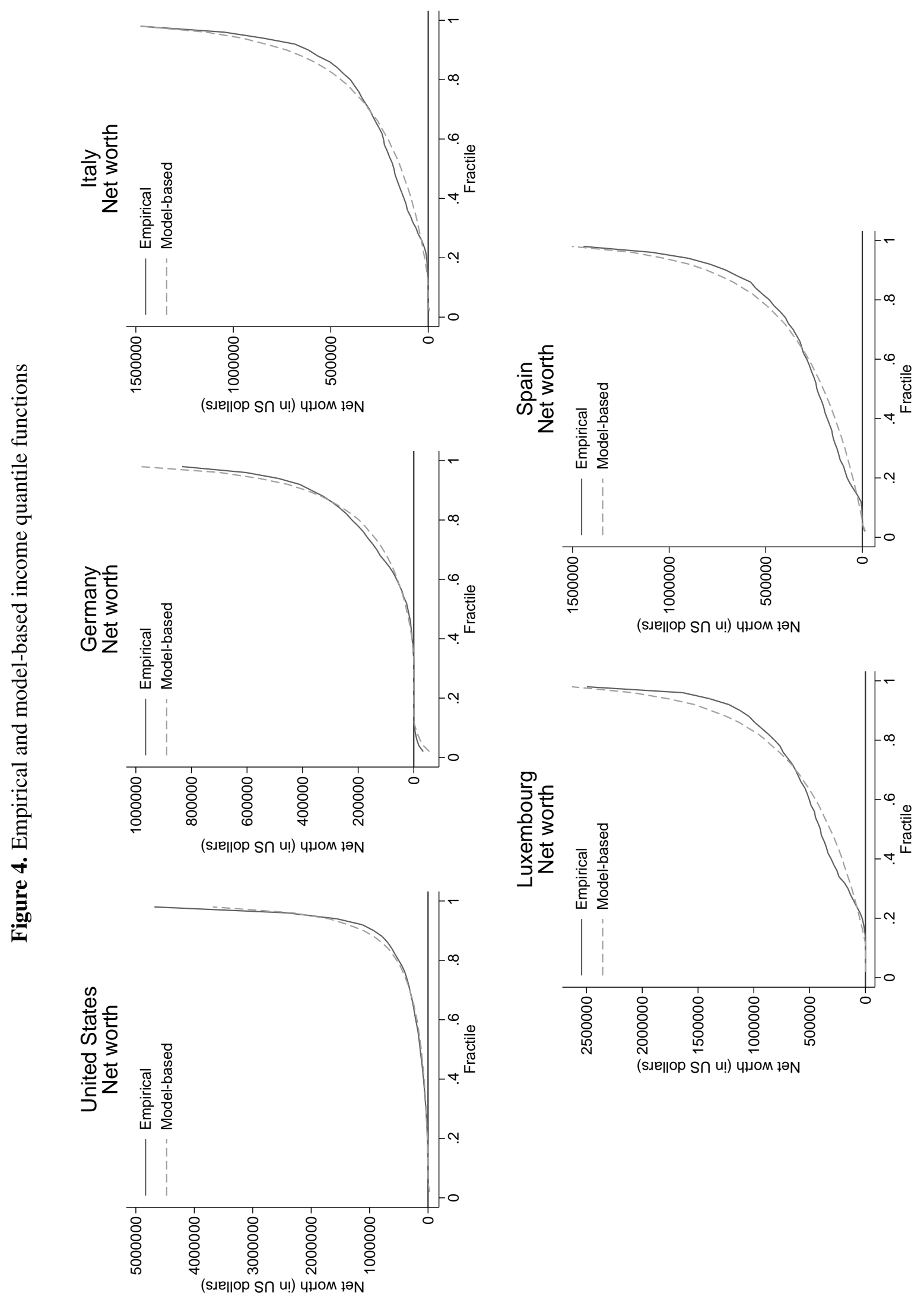


Figure 5. Empirical and model-based copula function
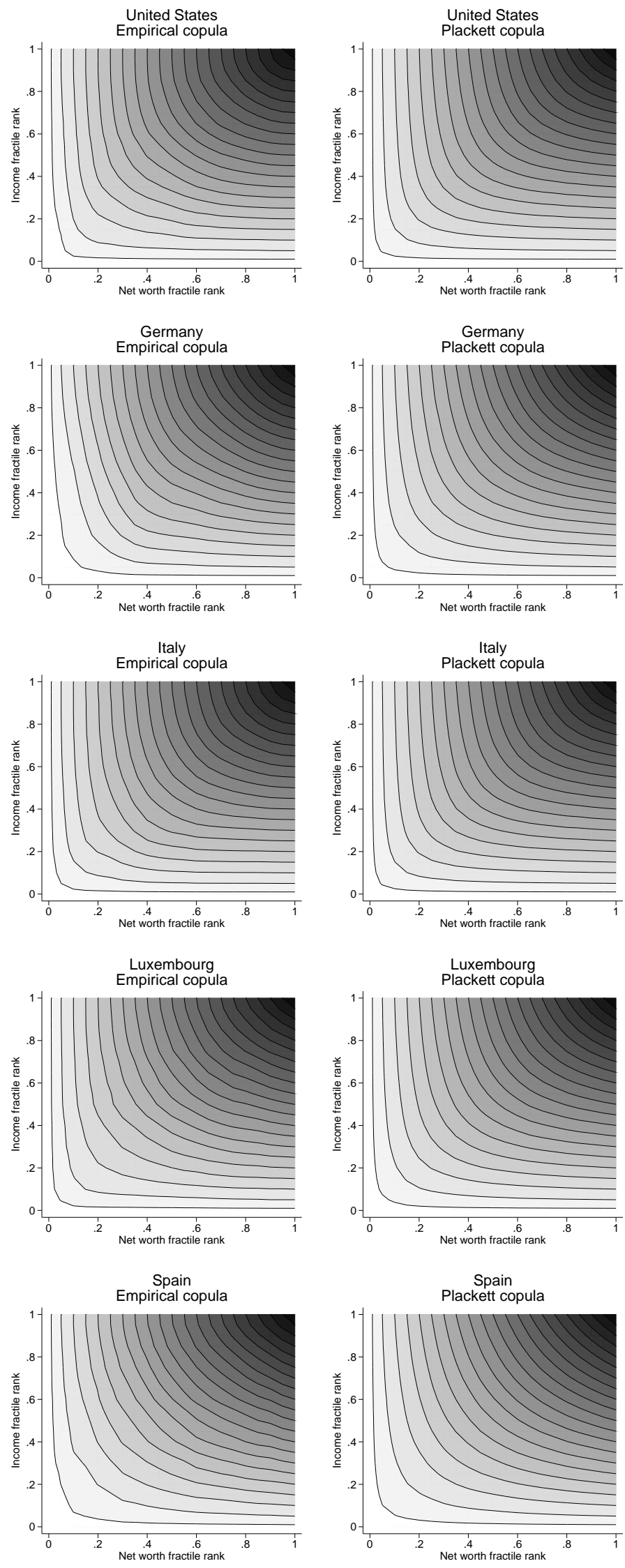